\title{
Space-Time Behavior of Single and Bimanual Rhythmical Movements: Data and Limit Cycle Model
}

\author{
B. A. Kay \\ Unıversity of Connecticut and Haskıns Laboratories, \\ New Haven, Connecticut \\ E. L. Saltzman \\ Haskıns Laboratorıes, New Haven, Connectıcut and \\ University of Connecticut
}

\author{
J. A. S. Kelso \\ Center for Complex Systems, Florida Atlantic University and \\ Haskıns Laboratorıes, New Haven, Connectıcut \\ G. Schöner \\ Center for Complex Systems, Florida Atlantic University
}

\begin{abstract}
How do space and time relate in rhythmical tasks that require the limbs to move singly or together in various modes of coordination? And what kind of minımal theoretıcal model could account for the observed data? Earlier findings for human cyclical movements were consistent with a nonlinear, limit cycle oscillator model (Kelso, Holt, Rubın, \& Kugler, 1981) al though no detaled modeling was performed at that time In the present study, kınematic data were sampled at 200 samples/second, and a detalled analysis of movement amplitude, frequency, peak velocity, and relative phase (for the bimanual modes, in phase and antiphase) was performed As frequency was scaled from 1 to $6 \mathrm{~Hz}$ (In steps of $1 \mathrm{~Hz}$ ) using a pacing metronome, amplitude dropped inversely and peak velocity increased Withın a frequency conditıon, the movement's amplitude scaled directly with its peak velocity These diverse kınematic behaviors were modeled explicitly in terms of low-dimensional (nonlınear) dissipative dynamics, with linear stiffness as the only control parameter Data and model are shown to compare favorably The abstract, dynamical model offers a unified treatment of a number of fundamental aspects of movement coordination and control
\end{abstract}

How do space and time relate in rhythmıcal tasks that require the hands to move singly or together in various modes of coordlnatıon? And what kınd of minimal theoretical model could account for the observed data? The present article addresses these fundamental questions that are of longstanding interest to experımental psychology and movement science (e g, von Holst, 1937/1973; Scripture, 1899; Stetson \& Bouman, 1935) It is well known, for example, that discrete and repetitive movements of different amplitude vary systematically in movement duration (provided accuracy requirements are held constant, e $g$, Craik, 1947a, 1947b) This and related facts were later formalized into Fitts's Law (1954), a relation among movement time, movement amplitude, and target accuracy, whose underpinnings have been extensively studied (and debated upon) quite recently (e g., Meyer, Smith, \& Wright, 1982; Schmidt, Zelaznık, Hawkıns, Frank, \& Quinn, 1979)

In the present study, the accuracy of movement is neither fixed nor manıpulated as in many investigations of Fitts's Law

Work on this article was supported by Natıonal Institute of Neurological and Communicative Disorders and Stroke Grant NS-13617, B10medical Research Support Grant RR-05596, and Contract N0014-83K-0083 from the U S Office of Naval Research G Schoner was supported by a Forschungsstipendium of the Deutsche Forschungsgemeinschaf, Bonn

Thanks to David Ostry, John Scholz, Howard Zelaznık, and three anonymous reviewers for comments

Correspondence concerning this article should be addressed to J A S Kelso, Center for Complex Systems, PO Box 3091, Florida Atlantıc Universtty, Boca Raton, Florida 33432
Only frequency is scaled systematically and amplitude allowed to vary in a natural way Surprisingly, there has been little research on movements performed under these partıcular experimental conditions (see Freund, 1983) Feldman (1980) reported data from a subject who attempted to keep a maximum ampl1tude (elbow angular displacement) as frequency was gradually increased to a lımitıng value $(7 \mathrm{lHz})$ An observed inverse relation was accompanied by an increasing tonic coactivation of antagonistic muscles. In addition, the slope of the so-called "1nvariant characterıstic" (see also Asatryan \& Feldman, 1965, Davis \& Kelso, 1982) -a plot of joint torque versus joint angle-increased with rhythmical rate, suggesting that natural frequency (or its dynamic equivalent, stiffness) was a controllable parameter. Other studies have scaled frequency but fixed movement amplitude Their conclusions were simular to Feldman's. Frequency changes over a range were accounted for by an increase in system stıffness (e g, Viviani, Soechting, \& Terzuolo, 1976)

Brooks and colleagues (e g, Conrad \& Brooks, 1974, see Brooks, 1979, for review) used a rather different paradigm for exploring spatiotemporal relations in cyclic movement patterns In several studies, monkeys produced rapid elbow flexions/extensions as they slammed a manipulandum back and forth between mechanical stops (thus allowing no variation in amplitude) After a trainıng period, the movement amplltudes were shortened artıficially by bringing the stops closer together The monkeys, however, contınued to exert muscular control for the "same" length of time, pressing the handle against the stops when they would normally have produced larger amplitude movements. Because the original rhythm of 
rapıd alterations established durıng trainıng was maintained in the closer-stop condition, "the rhythm . or some correlate of It" (Brooks, 1979, p. 23) was deemed to be centrally programmed However, it is not at all clear how these findings or conclusions relate to situations in which subjects are not prevented from adjustıng movement amplitude voluntarily in response to scalar increases in rate (see Schmidt, 1985).

With regard to less confined experimental paradigms in which speech and handwriting have been studied, several interesting results have come to light. As speaking rate is increased, for example, the displacement of observed articulator movements is reduced (e.g., Kelso, Vatıkıotıs-Bateson, Saltzman, \& Kay, 1985; Kent \& Moll, 1972, Ostry \& Munhall, 1985). The precise nature of the function relatıng these variables, however, is not known because only a few speaking rates have been employed in such experiments In handwriting, it is well known that when the amplitude of the produced letter is increased, movement duration remains approximately constant (e.g., Hollerbach, 1981; Katz, 1948; Vivianı \& Terzuolo, 1980). This handwriting result is theoretically interesting in at least two respects First, many interactıng degrees of freedom are involved in writing a letter, be it large or small, yet quite simple kinematic relations are reproducibly observed at the end effector Second, because the anatomy and bromechanics are entirely different between writıng on notepaper and on a blackboard, a rather abstract control structure is implicated.

In the present article we offer a dynamical model that is enturely consistent with such an abstract control structure and that is shown to reproduce observed space-tıme relations of limbs operating singly or together (in two specific modes of coordination) quite nicely Moreover, exactly the same model can be applied to transitions among coordinative modes of hand movement (see below). The present dynamical model is not tied locally and concretely to the biomechanics of the musculoskeletal periphery Rather, the approach is consistent with an older view of dynamics, namely, that it is the simplest and most abstract description of the motion of a system (Maxwell, 1877/1952, p 1). It is possible to use such abstract dynamics in complex multidegree of freedom systems when structure or patterned forms of motion arise (e.g., Haken, 1975, 1983). Such patterned regularitıes in space and time are characterized by low-dimensional dynamics whose variables are called order parameters One can imagine, for example, the high dimensionality involved in a simple finger movement were one to include a description of participating neurons, muscles, vascular processes, and so forth, along with their interconnections. Yet in tasks such as pointing a finger, the whole ensemble cooperates in such a way that it can be described by a simple, damped mass-spring dynamics for the end effector position. Thus, under the particular boundary conditions set by the pointing task, end position and velocity are the order parameters that fully specify the cooperative behavior of the ensemble Such "compression," from a microscopic basis of huge dimensıonality to a macroscopic, low-dimensional structure, is a general and predominant feature of nonequilibrium, open systems (e.g., Haken, 1983). In the context of movement, this reduction of degrees of freedom is characteristic of a coordinative structure, namely, a functional grouping of many neuromuscular components that are flexıbly assembled as a single, functional unit (e g, Kelso, Tuller, Vatikıotıs-Bateson, \& Fowler, 1984).

In earlier work (e g., Kelso, Holt, Kugler, \& Turvey, 1980; Kugler, Kelso, \& Turvey, 1980), we have identified such unitary ensembles-following Feldman (1966) -with the qualitative behavior of a damped mass-spring system Such systems possess a point attractor, that $1 \mathrm{~s}$, all trajectories converge to an asymptotic, static equilibrium state Thus, the property of equlfinality is exhibited, namely, a tendency to achieve an equilibrium state regardless of initial conditions The control structure for such motion can be characterized by a set of time-independent dynamic parameters (e g, stıffness, dampıng, equilıbrium position), with kınematic variations (e g., position, velocity, acceleration over tıme) emergung as a consequence This dynamıcal model has received a broad base of empirical support from studies of single, discrete head movement (Bizzı, Polit, \& Morasso, 1976), lımb movement (e g., Cooke, 1980, Polıt \& Bizzı, 1978; Schmidt \& McGown, 1980) and finger-movement targeting tasks (Kelso, 1977; Kelso \& Holt, 1980) In addition, point attractor dynamics can be shown to apply not only to the muscle-joint level but also to the abstract, task level of description as well (see Saltzman \& Kelso, 1987). That 1s, a dynamical description is appropriate at more than one "level." Strıkıng support for this notion has been recently accumulated by Hogan and colleagues (see Hogan, 1985) In their work on postural maintenance of the upper extremity, the well known "springlıke" behavior of a single muscle was shown to be a property of the entire neuromuscular system As Hogan (1985) notes, “

despite the evident complexity of the neuromuscular system, coordinative structures. . go to some length to preserve the simple 'spring-like' behavior of the single muscle at the level of the complete neuromuscular system" (p 166)

It is important to emphasize that point attractor dynamics provide a single account of both posture and targetıng movements Hence, a shift in the equilibrium position (corresponding to a given postural configuration) gives rise to movement (see e.g., Feldman, 1986). What, then, of rhythmical movement, our major concern here? It is easy to see, in principle, how a dynamical description might be elaborated to include this case For example, a single movement to a target may be underdamped, overdamped, or critically damped, depending on the system's parameter values (for example, see Kelso \& Holt, 1980). A simple way to make the system oscillate would be to change the sign of the damping coefficient to a negative value. This amounts to inserting "energy"' into the system. However, for the motion to be bounded, an additional dissipative mechanism must be present in order to balance the energy input and produce stable limit cycle motion. This combination of linear negative damping and nonlınear dissipative components comprises an escapement function for the system that is autonomous in the conventional mathematical sense of a time-independent forcing function.

In the present research we adopt this autonomous description of rhythmical movement, though we do not exclude-on em-

\footnotetext{
${ }^{1}$ It is important to emphasize here that we use terms like energy and dissipation in the abstract sense of dynamical systems theory (cf Jordan \& Smith, 1977, Minorsky, 1962) These need not correspond to any observable biomechanical quantities
} 
pirical grounds alone-the possibility that forcing may occur in a time-dependent fashion Oscillator theory tells us that nonlinear autonomous systems can possess a so-called periodic attractor or limit cycle; that is, all trajectories converge to a single cyclic orbit in the phase plane $(x, x)$ Thus, a nontrivial feature of both periodic attractor dynamics and rhythmical movement (entırely analogous to the foregoing discussion of point attractor dynamics and discrete movement) is stability in spite of perturbations and different initial conditıons.

In a set of experiments several years ago, we demonstrated such orbital stability (along with other behaviors such as mutual and subharmonic entrainment) in studies of human cyclical movements (Kelso, Holt, Rubın, \& Kugler, 1981) Although our data were consistent with a nonlunear limit cycle oscillator model for both single and coupled rhythmic behavior, no explict attempt to model the results was made at that time. More recently, however, Haken, Kelso, and Bunz (1985) have successfully modeled the circumstances under which observed transitions occur between two modes of coupling the hands-namely, antiphase motion of relative phase $\approx 180^{\circ}$, which involves nonhomologous muscle groups, and in-phase motion of relative phase $\approx 0^{\circ}$, in which homologous muscles are used The Haken et al (1985) nonlinearly coupled nonlinear oscillator model was able to reproduce the phase transition, that $\mathbf{1 s}$, the change in qualitative behavior from antiphase to in-phase coordination that occurs at a critical driving frequency, as the driving frequency ( $\omega$ ) was contınuously scaled (see Kelso, 1981, 1984, Mackenzie \& Patla, 1983). This model has been further extended in a quantitative fashion to reveal the crucial role of relative phase fluctuations in provokang observed changes in behavIoral pattern between the hands and to further identtfy the phenomenon as a nonequilibrium phase transition (Schoner, Haken, \& Kelso, 1986). Remarkably good agreement between Schoner et al.'s (1986) stochastic theory and experiments conducted by Kelso and Scholz (1985) and Kelso, Scholz, and Schoner (1986) has been found

In the present work we provide quantitative experimental results pertinent to the foregoing modeling work of Haken et al. (1985) and Schoner et al. (1986) For example, although the Haken et al. (1985) model provided a qualitative account of decreases in hand movement amplitudes with increasing frequency, the actual function relating these variables was not empirically measured in earher experiments nor was any fit of parameters performed. A goal of this research is to show how a rather simple dynamical model (or control structure)-requiring variations in only one system parameter-can account for the spatiotemporal behavior of the limbs acting singly and together The expermmental strategy was to have subjects perform cyclical movements in response to a metronome whose frequency was manipulated (1n $1-\mathrm{Hz}$ steps) between $1 \mathrm{~Hz}$ and 6 $\mathrm{Hz}$ The data reveal a stable and reproducible reciprocal relation between cycling frequency and amplitude for both single and bimanual movements. This constraint between the spatial and temporal aspects of movement patterns invokes immediately a nonlinear dynamical model (linear systems exhibit no such constraint), the particular parameters of which can be specified according to kinematsc observables (e.g., frequency, amplitude, and maximum velocity). Though we make no claims for the unıqueness of the present model, we do show that other models can be excluded by the data, and we suggest explicit ways in which uniqueness may be sought

\section{Method \\ Subjects}

The subjects were 4 right-handed male volunteers, none of whom were pand for their services They individually participated in two experimental sessions, which were separated by a week Each session consisted of approximately 1 hr of actual data collection

\section{Apparatus}

The apparatus was a modification of one described in detal on prev1ous occasions (Kelso \& Holt, 1980, Kelso et al, 1981) Essentially, it consisted of two freely rotating hand manupulanda that allowed flexion and extension about the wrist (radiocarpal) joint in the horizontal plane Angular displacement of the hands was measured by two DC potentiometers nding the shafts of the wrist positioners The outputs of the potentiometers and a pacing metronome (see below) were recorded with a 16-track FM tape recorder (EMI SE-7000)

\section{Procedure}

Subjects were placed in a dentist's chair, their forearms rigidly placed in the wrist-positioning device, so that the wrist joint axes were directly in line with the positioners' vertical axes Motion of the two hands was thus solely in the horizontal plane Vision of the hands was not excluded

Each experimental session was divided into two subsessions In the first session, single-handed movements were recorded, followed by twohanded movements, this was reversed for the second sesston Within each subsession, preferred movements were recorded, followed by metronome-paced movements For the preferred truals, subjects were told to move their wrists cyclically "at a comfortable rate" On the paced trials, subjects were told to follow the "beeps" of an audio metronome to produce one full cycle of motion for each beep. Pacing was provided for six different frequencies-1, $2,3,4,5$, and $6 \mathrm{~Hz}$-presented in random order For both the preferred and paced conditions, subjects were not instructed explicitly concerning the amplitude of movement; for example, they were not told to move their wrists maximally

For the single-hand subsession there were, therefore, 14 conditions, one preferred and six paced data sets being collected for each hand For the two-handed trials, there were also 14 conditions, one preferred and six paced data sets being collected for each of two different movement patterns These bimanual patterns consisted of a mirror, symmetric mode, which involved the simultaneous activation of homologous muscles and a parallel, asymmetric mode, which involved simultaneous activation of nonhomologous muscle groups (see, e g., Kelso, 1984) Two trials of data were collected for each condition in each session For the preferred trials, $30 \mathrm{~s}$ of data were collected, while $20 \mathrm{~s}$ were collected at the pacing frequencies of $1-4 \mathrm{~Hz}$, and $6 \mathrm{~s}-8 \mathrm{~s}$ at $5 \mathrm{~Hz}$ and $6 \mathrm{~Hz}$, to minimize fatigue effects

\section{Data Reduction and Dependent Measures}

Followng the experimental sessions, the movement signals were dig1tized at 200 samples/second and smoothed with a 35-ms triangular window Instantaneous angular velocity was computed from the smoothed displacement data by means of the two-point central difference algorithm and smoothed with the same triangular window (see Kay, Munhall, Vatıkıotıs-Bateson, \& Kelso, 1985, for detals of the signal processing steps involved) A cycle was defined by the occurrence of two (adja- 
Table 1

Mean Frequency, Amplitude, and Peak Veloctty for Single-Handed Trials

\begin{tabular}{|c|c|c|c|c|c|c|c|c|c|c|c|c|}
\hline Condition & \multicolumn{4}{|c|}{ Frequency $(\mathrm{Hz})$} & \multicolumn{4}{|c|}{ Amplitude (degrees) } & \multicolumn{4}{|c|}{ Peak velocity (degrees/second) } \\
\hline $\begin{array}{l}\text { Preferred } \\
\text { Paced }\end{array}$ & 204 & 38 & 204 & 33 & 4687 & 72 & 4688 & 64 & 31191 & 65 & 30708 & 61 \\
\hline $\begin{array}{l}1 \mathrm{~Hz} \\
2 \mathrm{~Hz} \\
3 \mathrm{~Hz} \\
4 \mathrm{~Hz} \\
5 \mathrm{~Hz} \\
6 \mathrm{~Hz}\end{array}$ & $\begin{array}{l}100 \\
200 \\
300 \\
402 \\
519 \\
633\end{array}$ & $\begin{array}{l}69 \\
37 \\
47 \\
6.5 \\
78 \\
69\end{array}$ & $\begin{array}{ll}1 & 00 \\
2 & 00 \\
3 & 00 \\
4 & 04 \\
5 & 14 \\
6 & 01\end{array}$ & $\begin{array}{l}49 \\
33 \\
40 \\
4.8 \\
49 \\
66\end{array}$ & $\begin{array}{ll}51 & 17 \\
43 & 11 \\
37 & 74 \\
38 & 64 \\
32 & 82 \\
26 & 81\end{array}$ & $\begin{array}{r}58 \\
76 \\
107 \\
107 \\
137 \\
218\end{array}$ & $\begin{array}{l}5354 \\
4601 \\
4050 \\
3354 \\
3335 \\
27 \quad 83\end{array}$ & $\begin{array}{r}70 \\
77 \\
81 \\
107 \\
96 \\
129\end{array}$ & $\begin{array}{ll}194 & 04 \\
291 & 19 \\
358 & 17 \\
463 & 31 \\
540 & 37 \\
516 & 89\end{array}$ & $\begin{array}{r}85 \\
82 \\
94 \\
90 \\
98 \\
109\end{array}$ & $\begin{array}{l}18740 \\
29862 \\
38045 \\
41685 \\
52210 \\
49933\end{array}$ & $\begin{array}{r}87 \\
78 \\
70 \\
86 \\
76 \\
107\end{array}$ \\
\hline
\end{tabular}

Note Means are collapsed across trials, sessions, and subjects Percentages represent average withın-trial cross-cycle coefficients of variation

cent) peak extension events, which, along with peak flexions, were identified by a peak-peakıng algorithm. Peak velocity was measured using the same peak picker on the velocity data, the values reported here are summaries across both positive and negative velocity peaks Cycle frequency (in $\mathrm{Hz}$ ) was defined as the inverse of the time between two peak extensions, and cycle amplitude (peak-to-peak, in degrees) as the average of the extension-flexion, flexion-extension half-cycle excursions For the two-handed trials, the relative phase (or phase difference) between the two hands was also computed on a cycle-by-cycle basis, using Yamanıshı, Kawato, and Suzuki's (1979) definitıon This is a purely temporal measure and is not computed from a motion's phase plane trajectory (Kelso \& Tuller, 1985) The measurement is based on the temporal location of a left peak extension within a cycle of righthand movement as defined above In our convention, for the mirror mode, phase differences of less than $0^{\circ}$ indicate that the left hand leads the right, and vice versa for positive values For the parallel, asymmetric mode, values of less than $180^{\circ}$ mean that the left hand leads the right ( $1 \mathrm{e}$, the left peak extension event is reached prior to exactly $180^{\circ}$ ), values greater than $180^{\circ}$ mean that the right hand leads For qualitative comparisons between model-generated simulations and data, phase plane trajectories were also examined These were created by simultaneously plottıng transduced angular position against the derived instantaneous velocity

After obtaining these measures for each cycle, we obtained measures of central tendency (means) and variability across all cycles of each trial
Coefficients of variation (CVs) were used as variability measures for frequency, amplitude, and peak velocity to remove the effects of the frequency scalıng on the mean data and thus to validly compare variability data across the observed frequency range The standard deviation was used as the phase variability measure, because coefficients of variation would be clearly inappropriate in comparing the two patterns of movement, whose mean phase differences were always around $0^{\circ}$ and $180^{\circ}$ In the following Results section are reported these withın-trial summary data, because of the large number of cycles collected In under $1 \%$ of the trials, a trial was lost because of experimenter error Thus, for statıstical purposes, means across trials withın each experımental condition were used

\section{Results}

The means and variability measures of frequency (in $\mathrm{Hz}$ ), amplitude (in degrees), peak velocity (in degrees/second) and relative phase (for the two-handed conditions) are presented in Tables 1 to 4 , collapsed across trials, sessions, and subjects. Both preferred and paced data are included in these tables

\section{Preferred Conditions}

\section{Frequency, Amplitude, and Peak Veloctty}

For both single and bimanual preferred movements, repeated measures analyses of variance (ANOVAS) were performed on the

Table 2

Mean Frequency, Amplitude, and Peak Velocity for Homologous (Mirror) Two-Handed Trials

\begin{tabular}{|c|c|c|c|c|c|c|c|c|c|c|c|c|}
\hline \multirow{2}{*}{ Condition } & \multicolumn{4}{|c|}{ Frequency $(\mathrm{Hz})$} & \multicolumn{4}{|c|}{ Amplitude (degrees) } & \multicolumn{4}{|c|}{ Peak velocity (degrees/second) } \\
\hline & \multicolumn{2}{|c|}{ Left } & \multicolumn{2}{|c|}{ Right } & \multicolumn{2}{|c|}{ Left } & \multicolumn{2}{|c|}{ Rught } & \multicolumn{2}{|c|}{ Left } & \multicolumn{2}{|c|}{ Right } \\
\hline $\begin{array}{l}\text { Preferred } \\
\text { Paced }\end{array}$ & 190 & 73 & 190 & 66 & 4149 & 40 & 4705 & 37 & 25293 & 73 & 28072 & 66 \\
\hline $\begin{array}{l}1 \mathrm{~Hz} \\
2 \mathrm{~Hz} \\
3 \mathrm{~Hz} \\
4 \mathrm{~Hz} \\
5 \mathrm{~Hz}\end{array}$ & $\begin{array}{ll}1 & 00 \\
2 & 00 \\
3 & 01 \\
4 & 08 \\
5 & 29\end{array}$ & $\begin{array}{ll}3 & 9 \\
3 & 5 \\
5 & 3 \\
81 & 1 \\
9 & 7\end{array}$ & $\begin{array}{l}100 \\
200 \\
300 \\
4.08 \\
525\end{array}$ & $\begin{array}{l}4.0 \\
33 \\
4.0 \\
57 \\
55\end{array}$ & $\begin{array}{ll}52 & 71 \\
38 & 80 \\
33 & 15 \\
30 & 50 \\
26 & 12\end{array}$ & $\begin{aligned} 62 \\
96 \\
110 \\
141 \\
176\end{aligned}$ & $\begin{array}{l}5685 \\
42 \quad 20 \\
3585 \\
3295 \\
2964\end{array}$ & $\begin{array}{r}60 \\
81 \\
96 \\
116 \\
135\end{array}$ & $\begin{array}{l}18830 \\
26085 \\
31845 \\
38718 \\
43064\end{array}$ & $\begin{array}{r}86 \\
94 \\
94 \\
95 \\
124\end{array}$ & $\begin{array}{l}19660 \\
28091 \\
34551 \\
41544 \\
47490\end{array}$ & $\begin{aligned} 82 \\
75 \\
81 \\
90 \\
112\end{aligned}$ \\
\hline
\end{tabular}

Note Means are collapsed across trials, sessions, and subjects only for the stable data Percentages show average withın-trial, cross-cycle coefficients of variation 
Table 3

Mean Frequency, Amplitude, and Peak Velocty for Nonhomologous (Parallel) Two-Handed Trals

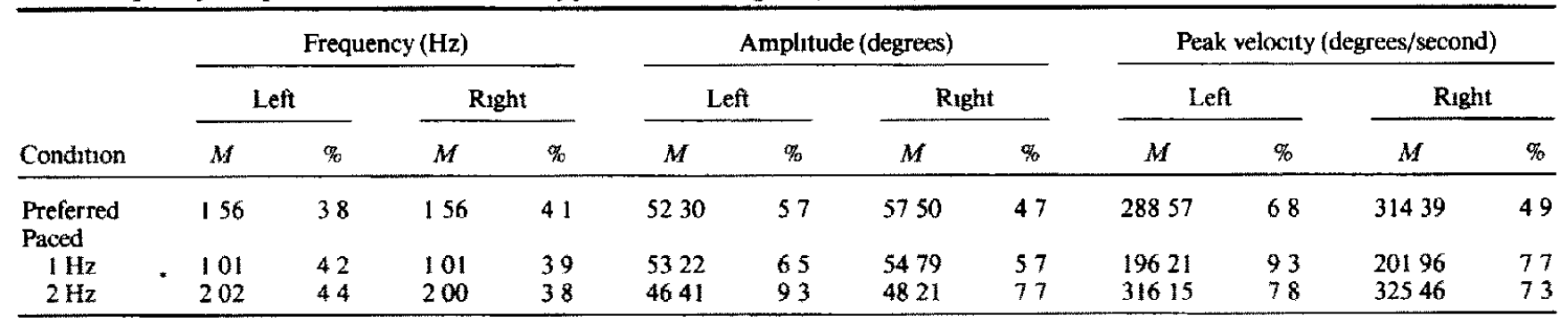

Note Means are collapsed across trials, sessions, and subjects only for the stable data Percentages represent average withın-trial, cross-cycle coeffclents of variation

within-trial means, and variabilty measures were obtained for frequency, amplitude, and peak velocity The design was a $2 \times$ $3 \times 2$ factorial, with hand (left, right), movement condition (sıngle, mirror, and parallel), and session as factors.

Mean data Looking first at frequency means, the only effect found was for movement condition, $F(2,6)=914, p<.05$. Post hoc Scheffe tests show that in the single $(2.04 \mathrm{~Hz})$ and mirror $(190 \mathrm{~Hz}$ ) mode the preferred frequencies were similar to each other but higher than in the parallel mode frequency $(1.56 \mathrm{~Hz})$. The two hands did not differ in preferred frequency in any of the three movement conditions With regard to amplitude means, a main effect for hand, $F(1,3)=14.16, p<.05$, and a Hand $\times$ Mode interaction, $F(2,6)=5.81, p<.05$, occurred. There was no significant movement condition effect, suggesting that the three movement conditions assumed the same amplitude in the preferred case. However, the interaction indicated that the amplitude means for the single conditions were identical for the two hands but differed in both bimanual conditions, the left hand assuming a lower amplitude than the right in each case No significant main effects or interactions were found for the preferred peak velocity data.

Variability data ANOVAS performed on the frequency and peak velocity withın-trial coefficients of variation revealed no

Table 4

Mean Relative Phase for Homologous (Mirror) and Nonhomologous (Parallel) Two-Handed Trials

\begin{tabular}{|c|c|c|c|c|}
\hline \multirow[b]{3}{*}{ Condition } & \multicolumn{4}{|c|}{ Relative phase (degrees) } \\
\hline & \multicolumn{2}{|c|}{ Homologous } & \multicolumn{2}{|c|}{ Nonhomologous } \\
\hline & $M$ & $S D$ & $M$ & $S D$ \\
\hline $\begin{array}{l}\text { Preferred } \\
\text { Paced }\end{array}$ & 646 & 1136 & 18528 & 1109 \\
\hline $\begin{array}{l}1 \mathrm{~Hz} \\
2 \mathrm{~Hz} \\
3 \mathrm{~Hz} \\
4 \mathrm{~Hz} \\
5 \mathrm{~Hz} \\
6 \mathrm{~Hz}\end{array}$ & $\begin{array}{r}360 \\
1044 \\
619 \\
400 \\
-581 \\
533\end{array}$ & $\begin{array}{r}675 \\
1084 \\
1800 \\
2636 \\
4253 \\
5191\end{array}$ & $\begin{array}{l}17775 \\
18599 \\
18882 \\
19364 \\
18168 \\
16888\end{array}$ & $\begin{array}{r}954 \\
1665 \\
5249 \\
9346 \\
10402 \\
11038\end{array}$ \\
\hline
\end{tabular}

Note Means $(M)$ are collapsed across trials, sessions, and subjects Standard deviations $(S D)$ are average within-trial, cross-cycle $S D$ s effects. For the amplitude CVs, however, there was a significant effect for movement condition, $F(2,6)=517, p<.05$. Post hoc tests showed that single-hand amplitudes were more variable than parallel amplitudes, which were more variable than those for mirror movements.

\section{Relattve Phase}

For the bimanual movement conditions, repeated measures ANOVAs were performed on the within-trial means and standard deviations of the relative phase between the two hands The design was a $2 \times 2$ factorial, Coordinative Mode (mirror and parallel) $\times$ Session. The only effect observed for phase was mode, $F(1,3)=13756.6, p<.0001$, showing that the subjects were indeed performing the task properly, producing two distinct phase relations between the hands The $95 \%$ confidence interval for the mirror mode was $6.56^{\circ} \pm 11.34^{\circ}$, and for the parallel mode, $185.28^{\circ} \pm 9.93^{\circ}$; the intervals overlap with the "pure" modes of $0^{\circ}$ and $180^{\circ}$, respectrvely (although in both modes the right hand tends to lead the left). There were no effects or interactions for phase variability in the preferred conditions.

\section{Metronome-Paced Conditions}

As can be seen in Tables 1-4, the manipulation of movement frequency had a profound effect on almost all the measured observables With increasing frequency, amplitude decreased, whereas peak velocity and all variability measures appeared to increase. There were some apparent differences among the three movement conditions as well, although the two hands behaved quite similarly. Valid comparisons among the experımental conditions on the kinematic variables of frequency, amplitude, and peak velocity can be made, however, only when it is established that subjects are actually performing the bimanual tasks in a stable fashion. Looking at Table 4, one can see that the phase variability of the two modes increased quite rapidly with increasing frequency.

In a $6 \times 2 \times 2$ factorial design, with pacing frequency (1-6 $\mathrm{Hz}$ in 1-Hz steps), coordinative mode (mirror and parallel), and session as factors, the only effect observed on the mean relative phase data was mode, $F(1,3)=233.01, p<.001$, and the means observed across all pacing frequencies were $421^{\circ}$ and $18293^{\circ}$ 
I.

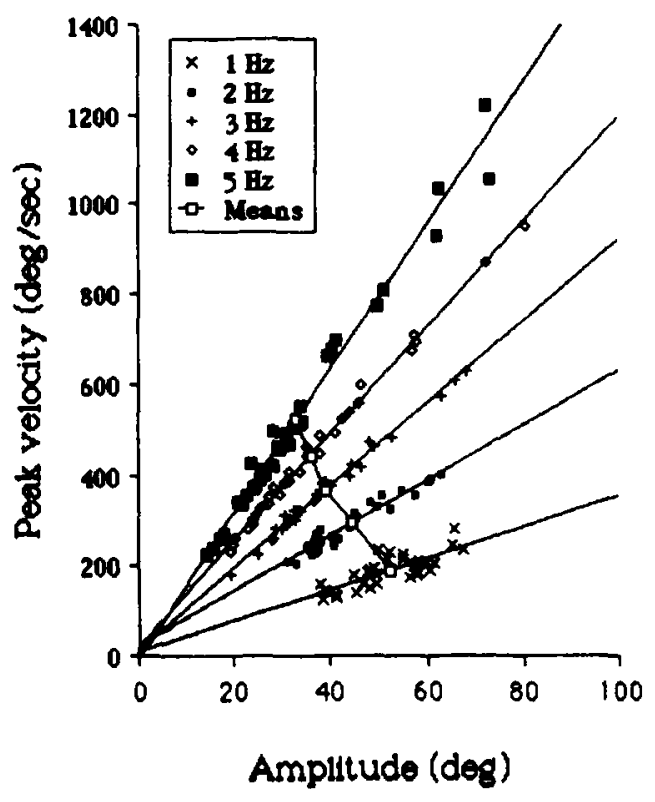

II.

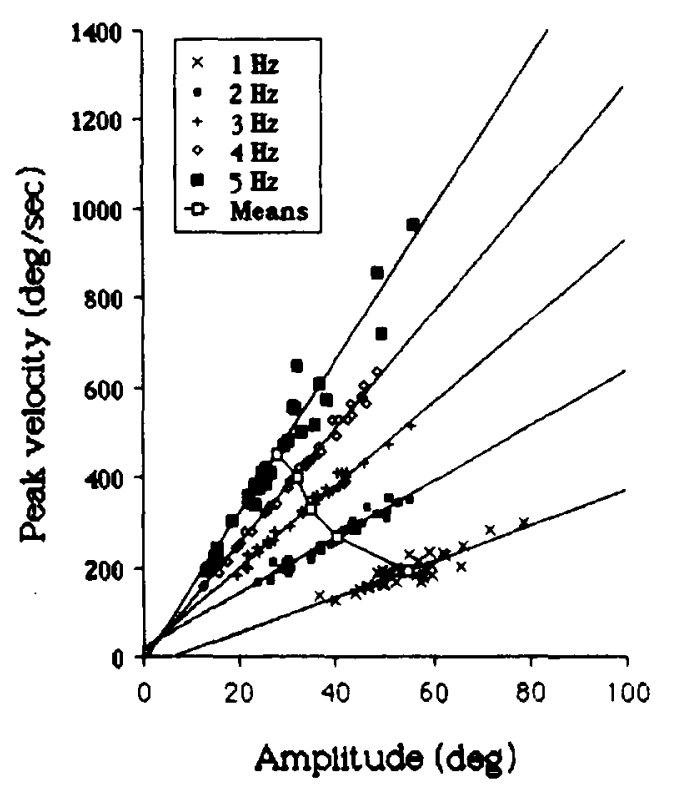

Figure 1 Amplitude (in degrees) and peak-velocity (in degrees/second) individual trial data for the 1-5 $\mathrm{Hz}$ pacing frequencies, and means within each frequency Left panel single-handed movements Right panel mirror-mode movements

in the mirror and parallel modes, respectively Apparently the two criterion phase angles are approximated, on the average. withın trials However, effects for pacing frequency, $F(5,15)=$ $124.91, p<.0001$, mode, $F(1,3)=26575, p<.001$, and their interaction, $F(5,15)=18.24, p<.001$, were found on the within-trial relative phase standard deviations. The interaction was consistent with both main effects: Variability in phase increased with increasing frequency for both modes, but the parallel mode's variabilty increased much faster than the mirror mode's Note, in Table 4, the order of magnitude increase in phase variability in the parallel mode between $2 \mathrm{~Hz}$ and $3 \mathrm{~Hz}$ A comparable degree of phase variability in the mirror mode is not evident until the 6- $\mathrm{Hz}$ pacing condition This result is consistent with other findings (e.g., Kelso, 1984; Kelso \& Scholz, 1985) that the parallel mode is highly unstable between $2 \mathrm{~Hz}$ and $3 \mathrm{~Hz}$ for similar movements, and a transition to the mirror mode is frequently observed above that frequency.

The foregoing pattern of phase varıability suggests, therefore, that we perform two separate analyses on the remainder of the paced data in order to make comparisons only within the stable regions of behavior. A reasonable criterion for phase stability is $\pm 45^{\circ}$ Thus, we now report (a) the analyses comparing mirror mode and single-hand behavior from $1 \mathrm{~Hz}$ to $5 \mathrm{~Hz}$ and (b) the analyses on all three movement conditions for $1 \mathrm{~Hz}$ and $2 \mathrm{~Hz}$.

\section{Single-Hand Versus Mirror-Mode Movements, $1-5 \mathrm{~Hz}$}

For single-hand and mirror-mode paced movements, repeated measures ANOVAS were performed on the within-trial means, and variabılity measures were obtained for frequency, amplitude, and peak velocity. The design was a $5 \times 2 \times 2 \times 2$ factorial, with pacing frequency ( $1-5 \mathrm{~Hz}$ in $1-\mathrm{Hz}$ steps), hand (left, right), movement condition (single and mirror) and session as factors

Mean data With regard to the observed frequency means, the pacing frequency was, as expected, a highly significant effect, $F(4,12)=111776, p<0001$ The only other effect present was a weak three-way interaction, Session $\times$ Hand $\times$ Pacing Frequency $F(4,12)=451, p<05$, indicating some very minor fluctuations in observed frequency. The main feature of this interaction is a simple effect for mode at the $3-\mathrm{Hz}$ pacing frequency, $F(2,6)=9.02, p<02$, which was observed for none of the other pacing frequencies

For the amplitude means, the main effect of pacing frequency, $F(4,12)=9.51, p<005$, shows that amplitude decreased with increasing frequency Three of the 4 subjects' linear correlations between amplitude and frequency were significant, (Pearson $r s=-.50,-86$, and $-87, p s<001$ ), while the 4th subject's amplitude trend, although decreasing, falled to reach significance $(r=-18, p=.12)$ The only other effect on ampltude was a weak three-way interaction, Mode $\times$ Hand $\times$ Pacing Frequency, $F(4,12)=330, p<05$, chiefly the result of the lefthand amphitude in the single case at $5 \mathrm{~Hz}$ being slightly higher than the rest of the data at that frequency Otherwise, no differences were found, the two movement conditions exhibitıng much the same amplitude across the entire frequency range Pacing frequency, $F(4,12)=8.26, p<.005$, was the only significant effect on the peak velocity means; the latter increased with increasing frequency for both movement conditions

The main effect of pacing frequency found for both ampltude and peak velocity indicates that each covaries with fre- 
quency of movement, but an interesting relation exists between the two With respect to the means across each pacing frequency, amplitude and peak velocity exhibited an inverse relation (see Figure 1) for both the single-hand and mirror movements $(r=-986$ for the single hands, $r=-958$ for the murror movements, on the overall means; $N=5$ and $p<.01$ for both correlations) At first, this result seems to contradict a wealth of findings on this relation which reveal that peak velocity scales directly with movement amplitude (see Kelso \& Kay, in press, for a review) However, an analysis of the individual trial data within a given pacing frequency condition indicates that peak velocity and amplitude do indeed scale directly with each other (see Figure 1) Pearson's $r$ correlations for each of the movement frequencies are listed in Table 5, and range from 772 to .997 ( $p<01$ in all cases) Slopes of the lines of best fit for peak velocity as a function of amplitude are also reported, none of the intercepts were significantly different from zero.

Variabiluty data The within-trial coefficients of variation (CVs) for observed frequency showed significant effects of pacIng frequency, $F(4,12)=13.68, p<.0005$, hand, $F(1,3)=$ $1259, p<05$, and the Pacing Frequency $\times$ Mode interaction, $F(4,12)=592, p<.01$ Overall, the left hand was more var1able in frequency than the right (CVs of $60 \%$ and $44 \%$, respectively) Analysis of simple main effects showed that pacing frequency was a significant effect for both single-hand and mirror movements, $F(4,12)=3.989, p<05$, and $F(4,12)=3324$, $p<0001$, respectively, but that the only difference between the two movement conditions occurred at $3 \mathrm{~Hz}, F(1,3)=20.18$, $p<.05$. At that pacing frequency, the mirror mode was slightly more variable than the single-hand movements.

The only significant effect on amplitude $C V s$ was pacing frequency, $F(4,12)=29.10, p<0001$ Amplitude vartability increased very consistently with increasing movement frequency (see also Figure 1, which shows the cross-trial variability in amplitude as well as in peak velocity). For the peak velocity CVs, session, $F(1,3)=1310, p<05$, and pacing frequency, $F(4,12)=3.51, p<.05$, were significant effects; variability in the second session was lower than that in the first (the only clearcut practice effect in the experiment), and higher frequency movements were consistently more variable on this measure

\section{Comparison of All Three Movement Conditions at $1 \mathrm{~Hz}$ and $2 \mathrm{~Hz}$}

For all three movement conditions, repeated measures ANOVAs were performed on the withın-trial means, and variability measures were obtained for frequency, amplitude, and peak velocity The design was a $2 \times 2 \times 3 \times 2$ factorial, with pacing frequency ( $1 \mathrm{~Hz}$ and $2 \mathrm{~Hz}$ ), hand (left, right), movement cond1tion (single, mirror, parallel), and session as factors.

Mean data For the observed frequency, pacing frequency, $F(1,3)=32708.6, p<0001$, and mode, $F(1,3)=664, p<$ 05 , were significant effects, with the parallel mode being slightly faster than the other two movement conditions overall. The difference, however, was less than $1 \%$ of the pacing frequency For amplitude, no main effects or interactions were found; the three movement conditions assumed a single overall amplitude, and amplitude differences were not apparent across the two observed frequencies For peak velocity, pacing fre- quency, $F(1,3)=1932, p<05$, and its interactions with movement condition, $F(2,6)=592, p<05$, and hand, $F(1,3)=$ $15.18, p<05$, were significant A simple main effects analysis for the first of these interactions indicated that the pacing frequency effect was significant for the single and parallel movements but not for the mirror mode. In addition, the movement conditions differed at $2 \mathrm{~Hz}$ (order from least to greatest peak velocity mirror, single, parallel) but not at $1 \mathrm{~Hz}$ The second interaction was consistent with the associated main effects-the pacing frequency effect was significant for both hands, and no simple effects for hand appeared However, at $2 \mathrm{~Hz}$ the right hand showed slightly greater peak velocities than the left. As observed for single-hand and mirror movements (see above), amplitude and peak velocity covaried directly in the parallel movements, within each pacing frequency (see Table 5).

Variabllity data For observed frequency, no main effects or interactions were found for the withın-trial CVs. For amplitude $\mathrm{CVs}$, the Movement Condition $\times$ Hand interaction was significant, $F(2,6)=1351, p<05$, yet no simple main effects were found at any level of the two independent variables However, for the left hand, both bimanual conditions were more variable than single-hand movements, whereas the reverse was true for the right. For peak velocity $\mathrm{CVs}$, the only effect was a weak three-way interaction of movement condition, hand, and frequency, $F(2,6)=7.87, p<.05$

\section{Qualltattve Results-Examples of Phase Portratts}

The shapes of the limit cycle trajectories can be very informative about the underlying dynamics. Figure 2 shows typical phase plane trajectories for single-hand movements; a section of one trial is displayed for each of the pacing frequencies from $1 \mathrm{~Hz}$ to $6 \mathrm{~Hz}$, along with the trajectories of the model (see next section on limit cycle models) at the same frequencies. As shown in the figure, trajectory shape vanes with movement frequency: Higher frequency movements appear to be somewhat more sinusoidal (1.e., more elliptical on the phase plane) than lower frequency ones This was especially apparent in going from $1 \mathrm{~Hz}$ to $2 \mathrm{~Hz}$. Some subjects showed this tendency less than others, but the shapes of the trajectories did not appear to differ among the three movement conditions. Note also that the velocity profiles are unımodal in these rhythmıcal movements, a result also observed in recent speech (Kelso et al., 1985) and discrete arm movements (e.g., Bizzı \& Abend, 1983; Cooke, 1980; Vivianı \& McCollum, 1983).

\section{Lımit Cycle Modeling}

In this section we first present a limit cycle model that accounts for a number of observed kınematıc characteristics of rhythmical hand movements, including the observed amplitude-frequency and peak velocity-frequency relations across conditions, as well as the peak velocity-amplitude relation withın a given pacing condition. In addition, an adequate generalization of the limit cycle model to coordinated rhythmic hand movements is presented (Haken et al., 1985), and conclusions are drawn from comparisons with the experimental data. A discussion of the assumptions that are implicit in our modeling strategy is deferred to the General Discussion 
Table 5

Correlations of Amplitude and Peak Velocty, Within Each Pacing Frequency, for Stable Frequencies

\begin{tabular}{|c|c|c|c|c|c|c|c|c|c|}
\hline \multirow{2}{*}{ Frequency } & \multicolumn{9}{|c|}{ Condition } \\
\hline & \multicolumn{3}{|c|}{ Single } & \multicolumn{3}{|c|}{ Mirror } & \multicolumn{3}{|c|}{ Parallel } \\
\hline $1 \mathrm{~Hz}$ & 772 & 344 & 32 & 903 & 398 & 30 & 733 & 462 & 26 \\
\hline $2 \mathrm{~Hz}$ & 970 & 608 & 32 & 972 & 619 & 32 & 967 & 658 & 32 \\
\hline $3 \mathrm{~Hz}$ & 995 & 909 & 32 & 992 & 915 & 32 & & & \\
\hline
\end{tabular}

Note $r=$ Pearson's $r, m=$ slope of the line of best fit (peak velocity as a function of amplitude), $N=$ number of trials for each correlation

As noted earlier by Haken et al. (1985), a combination of two well-known limit cycle oscillators is a strong candidate to model the observed monotonous decrease of amplitude as a function of frequency. These two oscillators are the van der Pol (van der Pol, 1922) and the Rayleigh oscillator (Rayleigh, 1877/1945) The first is described by an equation of motion of the following form:

$$
x+\alpha x+\gamma x^{2} x+\omega^{2} x=0,
$$

where $\alpha, \gamma$, and $\omega^{2}$ are constants. For $\alpha<0$ and $\gamma>0$, this equation has a limit cycle attractor. In a phase portrait in the $(x, x)$-plane this means that there is a closed curve on which the system rotates (the limit cycle) and to which all trajectories are attracted after a sufficiently long transient time. For $|\alpha| \ll \omega$ the frequency of oscillation on and near the limit cycle is, to a good approximation, just $\omega$ (see Minorsky, 1962, Section 10.6). Figure 3 illustrates this situation schematically.

An analytic description of the limit cycle can be given if the slowly varying amplitude and rotating wave approxımations are used (Haken et al , 1985, see Appendix A for a brief summary of the methods and the results) The amplitude of the limit cycle, which in this approximation is a harmonic oscillation, is found to be

$$
A=2 \sqrt{|\alpha| / \gamma}
$$

and is independent of the frequency $\omega$. Thus the van der Pol oscillator can account for the intercept of the amphtude-frequency relation but not for its monotonic decrease. The Rayleigh oscillator has the equation of motion,

$$
x+\alpha x+\beta x^{3}+\omega^{2} x=0,
$$

and possesses a limit cycle attractor for $\alpha<0, \beta>0$, again with an oscillation frequency $\omega$ as long as $|\alpha| \ll \omega$. Using again the two above-mentioned approximations, we obtain the amplitude of this limit cycle as

$$
A=(2 / \omega) \sqrt{|\alpha| / 3 \beta}
$$

(see Haken et al., 1985).

The decrease of amplitude with frequency observed in the data is captured by this expression, although the divergence of Equation 4 at small frequency is clearly nonphysical.

It is easy to imagine that a combination of both types of oscillators may provide a more accurate account of the experimental results Therefore, let us consider the following model.

$$
x+\alpha x+\beta x^{3}+\gamma x^{2} x+\omega^{2} x=0,
$$

which we refer to from now on as the "hybrid" oscillator For $\beta, \gamma>0, \alpha<0$ this yields again a limit cycle attractor of frequency $\omega$ (for $|\alpha| \ll \omega$ ) with amplitude (again in the approximations of Appendix A)

$$
A=2 \sqrt{|\alpha| /\left(3 \beta \omega^{2}+\gamma\right)}
$$

This function exhibits both a hyperbolic decrease in amplitude as well as a finte intercept at zero frequency and accounts qualtatively for the experimental data. In Figure 4 we have plotted the amplitude $A$ of the hybrid model together with the experimental data as a function of frequency The two parameters, $\beta$ and $\gamma$, were fitted (using a least squares fit, see Footnote 2 ) while $\alpha$ was chosen as $\alpha=-0.05 \times \omega_{\text {pref }}(=641 \mathrm{~Hz})$ without a further attempt to minimize deviations from the data (The values for $\beta$ and $\gamma$ were $\beta=.007095 \mathrm{~Hz}^{3}, \gamma=12457 \mathrm{~Hz}$, where $A$ was taken to be of the same scale as the experimental degree values.) The choice of $\alpha$ is consistent with the slowly varying amplitude approximation (for which we need $|\alpha| \ll \omega$; see Appendix A) and amounts to assuming that the nonlinearity is weak (see Appendix $B$ and General Discussion below). For illustrative purposes, the corresponding least squares fits for the van der Pol and the Rayleigh oscillators are also shown in Figure 4 Note that only one fit parameter, $\beta$ or $\gamma$ respectively, was used for these fits. It is obvious how each of the two foregoing models accounts for only one aspect of the experımental observations, and the hybrid model accounts for both. In summary, the model parameters were determined by (a) identıfyng the pacing frequency with $\omega$ (which is a good approximation for $|\alpha| \ll \omega$ ); (b) choosing $\alpha=-005 \times \omega_{\text {pref }}$; and (c) finding $\beta$ and $\gamma$ by a least squares fit of the amplitude-frequency relation. A more strıngent evaluation of the parameters is possible if more experimental information is avallable (see the discussion of the assump-

\footnotetext{
${ }^{2}$ The parameters $\beta$ and $\gamma$ were found by means of a pseudo-GaussNewton search for the parameters, using the single-hand observed frequency and amplitude trial data $(N=192)$ The least squares criterion was the minimization of squared residuals from the model amplitudefrequency function stated in Equation 6 The overall fit was found to be significant, $F(2,190)=35314, p<0001$, and the overall $R^{2}$ was 2748 , standard deviations for $\beta$ and $\gamma$ were $001025 \mathrm{~Hz}^{3}$ and $10129 \mathrm{~Hz}$, respectively
} 


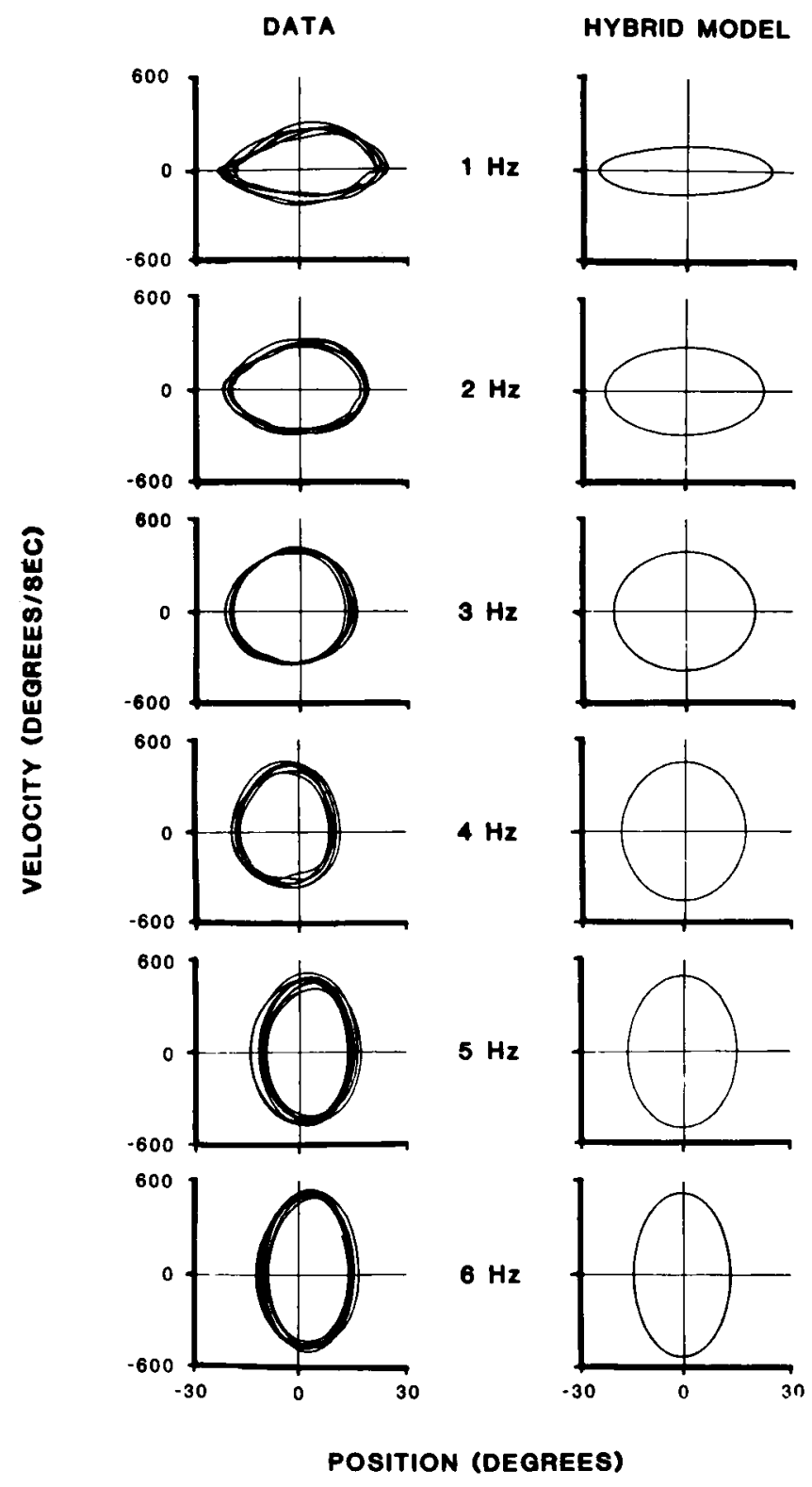

Figure 2 Phase plane trajectories from $1 \mathrm{~Hz}$ to $6 \mathrm{~Hz}$ Left panel representative examples from the collected data set of 1 subject $R$ ight paneltrajectories of the hybrid model (Equation 5), simulated on digital computer

tions in General Discussion below) Note, however, that even on this level of sophistication the model accommodates several further features of the data For example the peak velocity-amplitude relation given by the limit cycle model is the simple relation

$$
V_{p}=\omega A \text {. }
$$

This relation holds whenever the trajectory is close to the limit cycle Thus if trajectories fluctuate around the limit cycle (due to ever-present small perturbations), we expect the scatter of the peak velocity-amplitude data to lie on a straight line of slope $\omega$. Moreover, this same relation is shown to hold in the situation

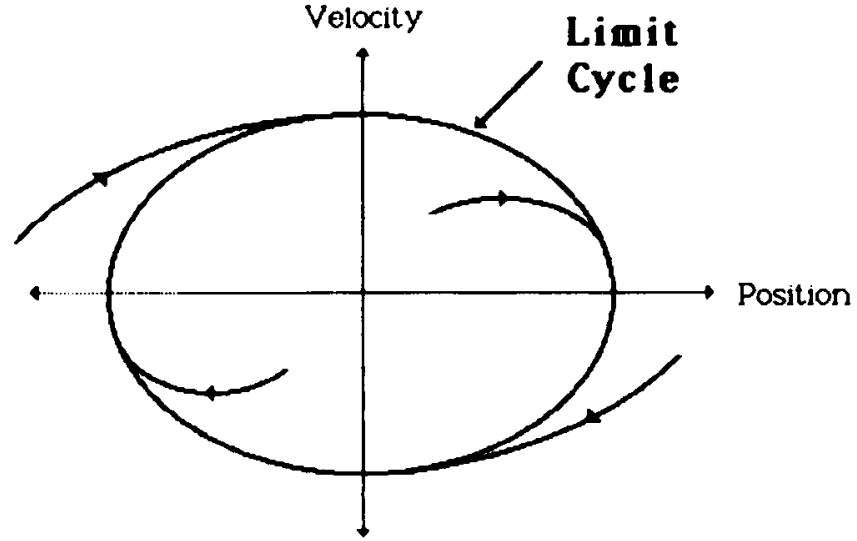

Figure 3 Examples of phase plane trajectories for a limit cycle

where amplitude varıes across trials (see Figure 1 and Table 5). Note that peak-to-peak amplitude equals $2 A$ so that the slopes reported in Table 5 are $\omega / 2=\pi \times$ Frequency. An additional piece of experimental information concerns the peak velocityfrequency relation (see Table 1 and Figure 5), the theoretical prediction for which results if we insert Equation 6 into Equation 7 as follows:

$$
V_{p}=2 \omega \sqrt{|\alpha| /\left(3 \beta \omega^{2}+\gamma\right)}
$$

This theoretical curve is also included in Figure 5 It is important to emphasize that all parameters have been fixed previously. Clearly, the match between model and experiment is quite close.

We now turn to the modeling of the two-handed movements. The essential idea is to couple two single-hand oscillators of type expressed in Equation 5. Assuming symmetry of the two hands, Haken et al., (1985) have established the most simple

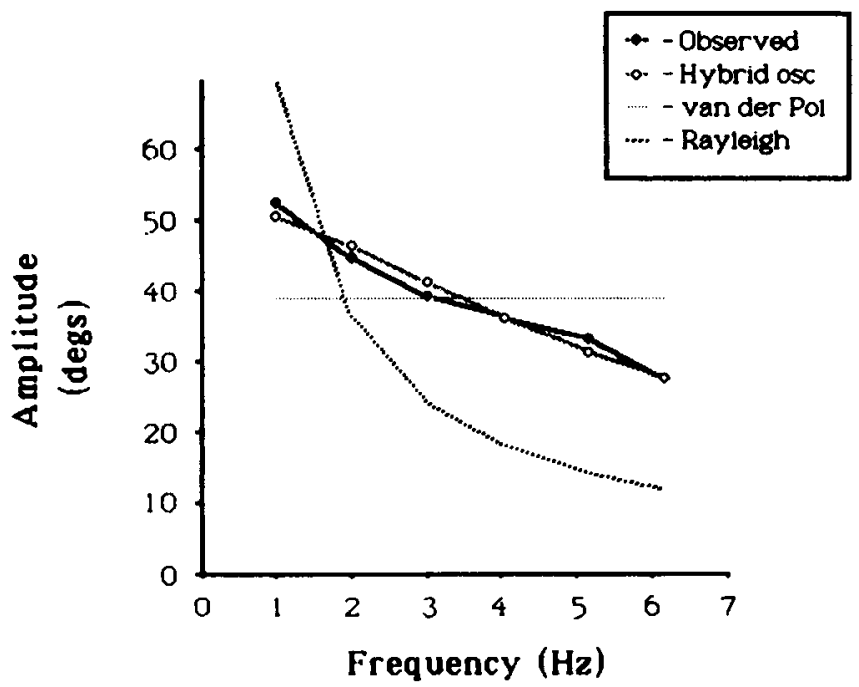

Figure 4 Frequency (in Hz) versus amplitude (in degrees) for the singlehanded data and the curves of best fit for the van der Pol, the Rayleigh, and the hybrid oscllators (The observed data are the mean values at each pacing frequency) 


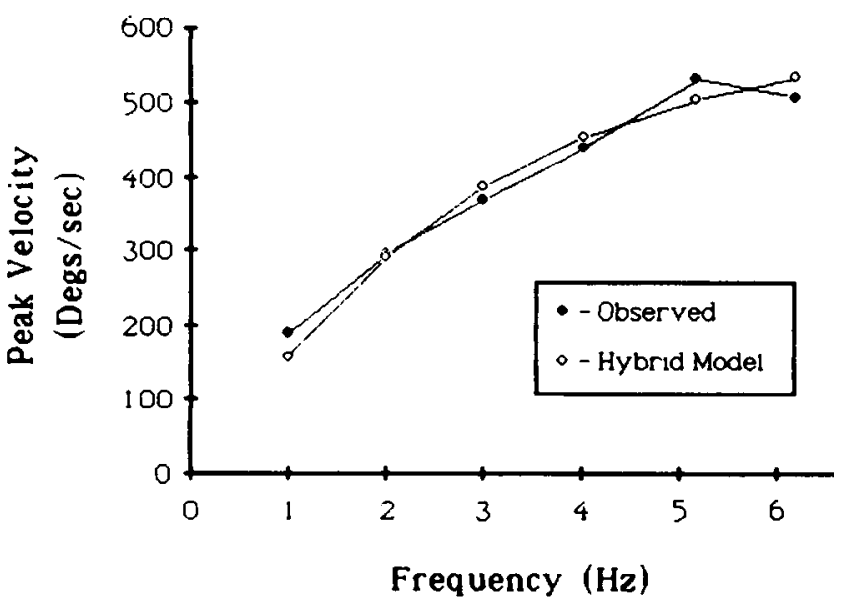

Figure 5 Frequency (in $\mathrm{Hz}$ ) versus peak velocity (in degrees/second) for the single-handed data and the corresponding function for the hybrid model (see Equation 8), as derived from the amplitude-frequency data (The observed data are the mean values at each pacing frequency)

coupling structure that accounts for both the in-phase (symmetric/mirror) and the antıphase (asymmetric/parallel) coordinative modes as well as the transition from an asymmetric to symmetric organization as frequency is scaled (see introduction) This coupling structure has the following explicit form

$$
\begin{aligned}
& x_{1}+g\left(x_{1}, x_{1}\right)=\left(x_{1}-x_{2}\right)\left[a+b\left(x_{1}-x_{2}\right)^{2}\right] \\
& x_{2}+g\left(x_{2}, \dot{x_{2}}\right)=\left(x_{2}-x_{1}\right)\left[a+b\left(x_{2}-x_{1}\right)^{2}\right],
\end{aligned}
$$

where

$$
g(x, x)=\alpha x+\beta x^{3}+\gamma x^{2} x+\omega^{2} x
$$

and $a$ and $b$ are coupling constants. Using again the approximatıons of Appendix A (see Haken et al., 1985, for the calculations), one obtains the amplitudes

$$
A_{1}=A_{2}=2 \sqrt{\frac{|\alpha|+a(1-\cos \phi)}{3 \beta \omega^{2}+\gamma-3 b+4 b \cos \phi-b \cos 2 \phi}} .
$$

In this expression $\phi=\phi_{2}-\phi_{1}$ is the relative phase of the two oscillators, which is $\phi= \pm 180^{\circ}$ for the asymmetric motion and $\phi=0^{\circ}$ for the symmetric motion. Note that for $a=b=0$ we recover the amplitude of the single hybrid oscillator (see Equatıon 6) Indeed, the experimental observation that the amplitudes of the two-handed modes of movement did not differ significantly from the single-hand amplitudes leads us to the conclusion that the coupling is weak in the sense that $a \ll \alpha$ and $b \ll$ $\gamma$ This is an interesting result in that it shows that even when the coupling is much weaker than the corresponding dissipative terms of the single-hand oscillators (which guarantee a stable amplitude-frequency relation), phase locking and transitions within phase lockıng can occur This may rationalize, to some degree, the ubiquity of phase locking in the rhythmical movements of anımals and people and is worthy of much more investigation.

A final remark concerns the preferred frequencies chosen by subjects in the single-hand condition compared with the two coordinative modes The observation was that the preferred frequency was always lower in the asymmetric mode than in either the symmetric mode or the single-hand movement conditions, which were roughly equal. As mentioned before, a transition takes place from the asymmetric mode to the symmetric mode as frequency is scaled beyond a certain critical value. The coupled oscillator model accounts for that transition in the sense that the stationary state $\phi \approx \pm 180^{\circ}$ for the relative phase becomes unstable (Haken et al., 1985). In fact, the stability of that state decreases when frequency increases, as exhibited by the relaxation rate of this state (see Schoner et al , 1986, and General Discussion). A simple analysis reveals that the preferred frequency in the asymmetric mode is shifted in such a way that the stability of the relative phase is larger than it would be if the preferred frequency of the single-hand oscillation were maintaned This observation may well be important for a fuller understanding of the preferred frequencies, in terms, perhaps, of varıatıonal princıples such as minımızatıon of energy (see Hoyt \& Taylor, 1981; Kelso, 1984)

\section{General Discussion}

In this article we have shown how a low-dimensional description in terms of dissipative dynamics can account-in a unified manner-for a number of observed facts. First, the present "hybrid" model includes the well-known mass-spring characteristic of postural tasks (see introduction). That is, when the linear damping coefficient, $\alpha$, is positive, the model exhibits a stable equilibrium position in the resting state $(x=0, x=0$ is a point attractor). Second, when the sign of the linear damping coefficient is negative, this equilibrium point is unstable, and an oscillatory solution with a frequency determined by the linear restoring force, $\omega^{2} x$, is stable and attracting The persistence of the oscillation and its stability is guaranteed by a balance between excitation (via $\alpha x$ with negative damping coefficient, $\alpha<0$ ), and dissipation (as indexed by the nonlinear dissipative terms, $\beta x^{3}$ and $\gamma x^{2} x$ ). This balance determınes the limit cycle, a per1odic attractor to which all paths in the phase plane $(x, x)$ converge from both the inside and the outside. For example, if $x$ or $x$ are large, corresponding to a condition outside the limit cycle, the dissipative terms dominate and amplitude will decrease. If, on the other hand, $x$ and $x$ are small, the linear excitation term dominates and amplitude will increase (see Figure 3) Third, oscillatory behavior is systematically modified by specific parameterizations, such as those created by a pacing manipulation. The model accounts for the amplitude-frequency and peak velocity-frequency relations with a simple change in one parameter, the linear stiffness $\omega^{2}$ (for unit mass). Further support for the latter control parameter comes from the direct scaling relation (observed within a pacing condition) of peak velocity and amplitude-a relation that is now well established in a variety of tasks (e.g , Cooke, 1980; Jeannerod, 1984; Kelso, Southard, \& Goodman, 1979; Kelso et al., 1985; Ostry \& Munhall, 1985; Vivianı \& McCollum, 1983). Thus, a number of kinematic characteristics and their relations emerge from the model's dynamic structure and parameterization. Fourth, and we believe importantly, the same oscillator model for the ind1vidual limb behavior can be generalized to the case of coordinated rhythmic action A suitable coupling of limit cycle (hy- 
brid) oscillators gives rise to transitions among modes of coordination when the pacing frequency reaches a critical value (Haken et al., 1985; Kelso \& Scholz, 1985; Schoner et al., 1986) Indeed, a number of additional phenomena can now be accommodated, including the "seagull effect" observed by Yamanıshı, Kawato, and Suzukı (1980) and Tuller and Kelso (1985, see Kelso, Schoner, Scholz, \& Haken, 1987, Section 6).

In summary, the model offers a synthesis of a variety of quite different movement behaviors that we have simulated explicitly on a digital computer (see Figure 2). That is, a successful implementation of the model has been effected that is now subject to further controlled experimentation. One appealing aspect of the model is that it formalizes and extends some of Feldman's (1966) early but influential work (see, e.g., Bizzı et al., 1976; Cooke, 1980; Kelso, 1977; Ostry \& Munhall, 1985; Schmıdt \& McGown, 1980). Feldman (1966) presented observations on the execution of rhythmic movement that strongly suggested that the nervous system was capable of controlling the natural frequency of the joint using the so-called invariant characteristıcs-a plot of joint angle versus torque (see also Berkenblit, Feldman, \& Fukson, 1986, Davis and Kelso, 1982). But he also recognized that "a certain mechanism to counteract damping in the muscles and the joint" must be brought into play, in order to "make good the energy losses from friction in the system" (Feldman, 1966, p. 774). Our model shows-in an abstract sense-how excitation and dissipation balance each other so that stable rhythmic oscillations may be produced

On the other hand, in modeling movement in terms of lowdimensional, nonlinear dynamics, we have made certain assumptions that will now be addressed, because they require additıonal experimental test. For reasons of clarity we list these modeling assumptions systematically.

1. Equifinality. This is a pivotal issue of the entire approach The very fact that the oscillatory movement pattern can be reached reproducibly from uncontrolled initial conditions indicates-as far as the theory is concerned-that (a) a description of the system dynamıcs in terms of a sıngle variable (a displacement angle about a single rotation axis) and its derivative is sufficient - that is, there are no hidden dynamical variables that influence the movement outcome-and that (b) the modeling in terms of a low-dimensional description must be dissipative in nature (allowing for attractor sets that are reached independent of initial conditions). An experımental test of the equifnality property consists of studying the stability of the movement pattern under perturbations. Although such stability was observed in earlier studies (Kelso et al., 1981), a much more systematic investigation is now required.

2 Autonomy. A further reduction in the number of relevant variables is possible through the assumption of autonomous dynamics. Nonautonomous forcing - as mentioned in the introduction-essentially represents one additional variable, namely, tıme itself. Apart from the conceptual advantages discussed in the introduction, there are experimental ways to test this assumption. One such method consists of studying phase resetting curves in perturbation experıments (Winfree, 1980). For example, in a system driven by a tume-dependent forcing function (e g., a driven damped harmonic oscillator), perturbations will not introduce a permanent phase shift. On the other hand, if consistent phase shifts are observed in the data, the rhythm cannot be due fundamentally to a nonautonomous driving element

A strong line of empirical support for the autonomy assumption comes from the transition behavior in the bimanual case, as frequency is scaled (Kelso, 1981, 1984; Kelso \& Scholz, 1985). Here autonomous dynamics were able to account for the transition behavior in some detal (Haken et al., 1985; Schoner, et al. 1986). Note also that durnng the transition one or both of the hands must make a shıft in phase, a result that would require a not easily understood change in the perıodic forcing function(s); that is, one or both "timing programs" would have to alter in unknown ways to accomplish the transition

3 Minimality The effective number of system degrees of freedom can be further limited by the requirement that the model be minimal in the following sense. The attractor layout (1.e., the attractors possible for varying model parameters) should include only attractors of the observed type In the present single-hand case, for example, the model should not contain more than a (monostable) limit cycle and a single fixed point (corresponding to posture). This limits the dynamics to those of second order: Higher orders would allow, for example, quasiperiodic or chaotic solutions (e.g., Haken, 1983), which have not been observed thus far

The above considerations (equifinality, autonomy, and mınımality) thus constrain the number of possible models considerably. Explicitly, the most general form of the model given these constraints is

$$
x+f(x, x)=0
$$

We can illustrate the relation of the hybrid model to the general case (Equation 13) by expanding $f$ in a Taylor series (assuming symmetry under the operation $x \rightarrow-x$, as inferred to be a good approximation from the phase portrats [Figure 2]), as follows.

$$
\dot{x}=\omega^{2} x+\alpha x+\beta x^{3}+\gamma x^{2} x+\delta x x^{2}+\epsilon x^{3}+O\left(x^{5}, x x^{4}\right)
$$

The hybrid model (Equation 5) then results from putting $\delta=\epsilon=0$

Our discussion of modeling assumptions can be drawn to a close by remarking that more detailed information about the system dynamics can now be gained by asking experimental questions that are motivated by the theory. For example, in the model the system's relaxation tıme (1.e., the time taken to return to the limit cycle after a perturbation) is approximately the inverse of $\alpha$ (see Appendix A), which a simple dimensional analysis reveals to be related to the strength of the nonlinearity (see Appendix B). Thus, relaxation time measurements can give Important information about how and by how much the system supples and dissipates "energy" in its oscillatory behavior (where energy is to be understood as the integral along $x$ of the right-hand side of Equation 14; see Jordan \& Smrth, 1977, and Footnote 1). In another vein, it should be recognized that the model's dynamics are entirely determinustic in their present form. Stochastic processes, which have been shown quite recently to play a crucial role in effecting movement transitions (Kelso \& Scholz, 1985; Kelso, Scholz, \& Schoner, 1986; Schoner et al., 1986), have not been considered. However, these processes are probably present, as evidenced, for example, in the scatter of amplitudes at a given oscillation frequency. Stochastic properties of rhythmic movement patterns may be ex- 
plored independent of perturbation experiments by appropriate spectral analysis of the time-series data (see, e.g., Kelso \& Scholz, 1985) Elaboration of the model to incorporate stochastic aspects is warranted and is a goal of further research.

A final comment concerns the physiological underpinnings of our behavioral results. With respect to the present model, such underpinnings are obscure at the moment. Just as there are many mechanisms that can achieve macroscopic ends, so too there are many mechanısms that can instantiate limit cycle behavior (for a brief discussion, see Kelso \& Tuller, 1984, pp 334-338) The aim here has been to create a model that can realize the stablity and reproducibility of certain so-called "sımple" movement behaviors. Whatever the physiological bases of the latter, our argument is that they must be consistent with low-dimensional dissipative dynamics. There is not necessarily a dichotomy between the present macroscopic account, which stresses kinematic properties as emergent consequences of an abstract dynamical system, and a more reductıonıstic approach, which seeks to explain macrophenomena on the basis of microscopic properties. The basis for explanation of a complex phenomenon like movement may be the same (1.e., dynamical) at all levels within the system, operative, perhaps, on different tıme scales

\section{References}

Asatryan, D G , \& Feldman, A. G (1965) Functional tuning of the nervous system with control of movement or maintenance of a steady posture I Mechanographic analysis on the work of the joint on execution of a postural task Biophysics, 10, 925-935

Berkenblit, M B , Feldman, A G , \& Fukson, O I (1986) Adaptability of innate motor patterns and motor control mechanisms Behavioral and Brain Sclences, 9, 585-638

Bizzi, E , \& Abend, W (1983) Posture control and trajectory formation in single and multiple joint arm movements In J E Desmedt (Ed), Brain and spinal mechanisms of movement control in man (pp 3145) New York Raven

Bizzl, E, Polit, A , \& Morasso, P (1976) Mechanisms underlyıng achievement of final head position Journal of Neurophysiology, 39, 435-444

Brooks, V B (1979) Motor programs revisited In R E Talbott \& D R Humphrey (Eds), Posture and movement (pp 13-49) New York Raven

Conrad, B , \& Brooks, V B (1974) Effects of dentate coolıng on rapıd alternatıng arm movements Journal of Neurophysiology, 37, 792804

Cooke, J D (1980) The organization of simple, skılled movements In G E Stelmach \& J Requin (Eds), Tutonals in motor behavior (pp 199-212) Amsterdam North-Holland

Cralk, K J W (1947a) Theory of the human operator in control systems 1 The operator as an engineering system Brttsh Journal of Psychology, 38, 56-61

Craik, K J W (1947b) Theory of the human operator in control systems. II Man as an element in a control system British Journal of Psychology, 38, 142-148

Davis, W E , \& Kelso, J A S (1982) Analysıs of invariant characterıstics in the motor control of Down's syndrome and normal subjects Journal of Motor Behavor, 14, 194-212

Feldman, A G (1966) Functional tuning of the nervous system with control of movement or mantenance of a steady posture III. Mechanographic analysis of execution by man of the simplest motor tasks Biophysics, $11,766-775$
Feldman, A G (1980) Superposition of motor programs I Rhythmic forearm movements in man Neuroscience, 5, 81-90

Feldman, A G. (1986) Once more on the equilibrium point hypothesis Journal of Motor Behavior, 18, 17-54

Fitts, P M (1954) The information capacity of the human motor system in controlling the amplitude of movement Journal of Expertmental Psychology, 47, 381-391

Freund, H -J (1983) Motor unit and muscle activity in voluntary motor control Physiological Reviews, 63, 387-436

Haken, H. (1975) Cooperative phenomena in systems far from thermal equilibrium and in nonphysical systems Review of Modern Physics, $47,67-121$

Haken, H (1983) Advanced synergetics Heidelberg Springer-Verlag

Haken, H (1985) Laser light dynamics Amsterdam North-Holland

Haken, H , Kelso, J. A S , \& Bunz, H (1985) A theoretical model of phase transitions in human hand movements Biological Cybernetics, 51. 347-356

Hollerbach, J (1981) An oscillator theory of handwriting Biological Cybernetics, 39, 139-156

Hogan, N (1985) Control strategies for complex movements denved from physical systems theory In $\mathrm{H}$ Haken (Ed), Complex systems Operational approaches in neurobiology, physics, and computers (pp 156-168) Heidelberg: Springer-Verlag

Holst, E von (1973) On the nature of order in the central nervous system In The behavioral physiology of animals and man The collected papers of Erich von Holst (pp 3-32) Coral Gables, FL. University of Miamı Press (Onignal work published 1937)

Hoyt, D F, \& Taylor, C R (1981) Gait and the energetics of locomotion in horses. Nature, 292, 239-240

Jeannerod, $M$ (1984) The tımıng of natural prehensıle movements Journal of Motor Behavior, 16, 235-254

Jordan, D W, \& Smith, P (1977) Nonlinear ordinary differentıal equations Oxford Clarendon Press

Katz, D (1948) Gestaltpsychologie [Gestalt psychology] Basel Schwabe

Kay, B., Munhall, K G , Vatıkıotıs-Bateson, E , \& Kelso, J A S (1985) A note on processing kinematic data Sampling, filterıng, and differentiation Haskıns Laboratortes Status Report on Speech Research, SR-81, 291-303

Kelso, J A S (1977) Motor control mechanisms underlying human movement reproduction Journal of Experimental Psychology $\mathrm{Hu}$ man Perception and Performance, 3, 529-543

Kelso, J A S. (1981) On the oscillatory basis of movement Bulletın of the Psychonomic Society, 18,63

Kelso, J A. S (1984) Phase transitions and critical behavior in human bimanual coordination American Journal of Physiology Regulatory, Integrative, and Comparative, 246, R 1000-R 1004

Kelso, J A S , \& Holt, K G (1980) Explorıng a vibratory systems analysis of human movement production Journal of Neurophysiology, 43, 1183-1196

Kelso, J A S., Hoit, K G, Kugler, P N, \& Turvey, M T (1980) On the concept of coordınative structures as dissipative structures II Empirical lines of convergence In G E. Stelmach \& J Requin (Eds), Tutorials in motor behavior (pp 49-70) New York North-Holland

Kelso, J A S , Holt, K G, Rubın, P, \& Kugler, P N (1981) Patterns of human interlimb coordination emerge from the properties of nonlinear limit cycle oscillatory processes Theory and data Journal of Motor Behavior, 13, 226-261

Kelso, J A S , \& Kay, B (in press) Information and control A macroscopic basis for perception-action coupling To appear in $\mathrm{H}$ Heuer \& A F Sanders (Eds), Tutorials in perception and action Hillsdale, $\mathrm{N} \mathrm{J}$ Erlbaum

Kelso, J A S , \& Scholz, J P (1985) Cooperative phenomena in biological motion In H Haken (Ed), Complex systems Operational ap- 
proaches in neurobiology, physics, and computers (pp 124-149) New York Springer-Verlag

Kelso, J A S, Scholz, J P, \& Schoner, G (1986) Nonequilibrium phase transitions in coordinated biological motion Critical fluctuations Physics Letters A, 118, 279-284

Kelso, J A S, Schoner, G, Scholz, J P, \& Haken, H (1987) Phaselocked modes, phase transitions and component oscillators in biological motion Physica Scripta, 5, 79-87

Kelso, J A S , Southard, D L , \& Goodman, D (1979) On the coord1nation of two-handed movements Journal of Experimental Psychology Human Perception and Performance, 5, 229-238

Kelso, J A S , \& Tuller, B (1984) A dynamical basis for action systems In M S Gazzaniga (Ed), Handbook of cognitive neuroscience (pp 321-356) New York Plenum

Kelso, J A S , \& Tuller, B (1985) Intrinsic tıme in speech production Theory, methodology, and prelıminary observations Haskins Laboratories Status Report on Speech Research, SR-81, 23-39 Also (1n press) in E Keller \& M Gopnik (Eds.), Sensory and motor processes in language Hillsdale, NJ Erlbaum

Kelso, J A S, Tuller, B, Vatıkıotıs-Bateson, E , \& Fowler, C A (1984) Functionally specific articulatory cooperation following jaw perturbation durıng speech Evidence for coordinative structures Journal of Experimental Psychology Human Perception and Performance, 10. 812-832

Kelso, J A S , Vatıkıotıs-Bateson, E , Saltzman, E L , \& Kay, B (1985) A qualitative dynamic analysis of retterant speech production Phase portraits, kınematıcs, and dynamic modeling Journal of the Acoust cal Society of America, 77, 266-280

Kent, R D , \& Moll, K L (1972) Cinefluorographic analyses of selected lingual consonants Journal of Speech and Hearing Research, $15,453-473$

Kugler, P N , Kelso, J A S, \& Turvey, M T (1980) On the concept of coordinative structures as dissipative structures. I Theoretical lines of convergence In G E Stelmach \& J Requin (Eds), Tutorials in motor behavior (pp 3-47) New York North-Holland

MacKenzie, C L , \& Patla, A E (1983) Breakdown in rapıd bımanual finger tapping as a function of orientation and phasing Soclety for Neuroscience (Abstract)

Maxwell, J C (1952) Matter and motion New York Dover (Orıgınal work published 1877)

Meyer, D E , Smith, J E , \& Wright, C E. (1982) Models for speed and accuracy of aimed movements Psychological Review, 89, 449-482

Minorsky, N (1962) Nonlinear oscillations Princeton, NJ Van Nostrand

Ostry, D J , \& Munhall, K (1985) Control of rate and duration in speech Journal of the Acoustical Soctety of America, 77, 640-648
Polit, A , \& Bizzı, E (1978) Processes controlling arm movements in monkeys Science, 201, 1235-1237

Rayleıgh, Baron (John Willam Strutt) (1945) Theory of sound (Vol 1) New York Dover (Oniginal work publıshed 1877)

Saltzman, E L , \& Kelso, J A S (1987) Skılled actions A task dynamic approach Psychological Review, 94, 84-106

Schmidt, R A (1985, November) "Motor" and "action" perspectives on motor behavior Some important differences, mainly common ground Paper presented at the conference entitled "Perspectives on Motor Behavior and Control" at the Zentrum fur interdisziplınare Forschung (Center for Interdısciplinary Research), Universıtat Bielefeld, West Germany

Schmidt, R A., \& McGown, C (1980) Terminal accuracy of unexpectedly loaded rapid movements Evidence for a mass-spring mechanism in programming Journal of Motor Behavior, 12, 149-161

Schmıdt, R A, Zelaznık, H N, Hawkıns, B, Frank, J S, \& Quinn, J T, Jr (1979) Motor-output variability A theory for the accuracy of rapid motor acts Psychological Review, 86, 41 S-451

Schoner, G, Haken, H , \& Kelso, J A S (1986) A stochastic theory of phase transitions in human hand movements Blological Cybernetics, 53. 247-257

Scripture, E W (1899) Observations of rhythmic action Studies from the Yale Psychological Laboratory, 7, 102-108

Stetson, R. H , \& Bouman, H D (1935) The coordination of simple skılled movements Archives de Neérlandaises de l'Homme et des Animaux, 20, 179-254

Tuller, B , \& Kelso, J A S (1985, November) Bimanual coordınation following commissurotomy. Paper presented at the meetıng of the Psychonomic Society, Boston, MA

Viviani, P, \& McCollum, G (1983) The relation between linear extent and velocity in drawing movements Neuroscience, 10, 211-218

Vivianı, P, Soechtıng, J F, \& Terzuolo, C. A. (1976) Influence of mechanical properties on the relation between EMG activity and torque Journal of Physiology (Paris), 72, 45-52

Vıvianı, P, \& Terzuolo, V (1980) Space-tıme invariance in learned motor skılls In G E Stelmach \& J Requin (Eds.), Tutorials in motor behavior (pp 525-533). Amsterdam. North-Holland

van der Pol, B (1922). On oscillation hysteresis in a triode generator with two degrees of freedom Philosophical Magazine, 43, 700-719

Winfree, A T (1980) The geometry of biological time New York Sprınger-Verlag.

Yamanıshı, J, Kawato, M , \& Suzuka, R (1979) Studies on human finger tapping neural networks by phase transition curves Biological Cybernetıcs, 33, 199-208

Yamanıshı, J , Kawato, M , \& Suzukı, R. (1980) Two coupled oscillators as a model for the coordinated finger tapping by both hands Biological Cybernetics, 37, 219-225 


\section{Appendix A}

\section{Limit Cycle Model Calculations}

In this appendix we illustrate some of the basic tools employed in the model calculations in terms of the van der Pol oscillator For an introduction to such techniques see, for example, Haken (1983), Jordan and Smith (1977), and Minorsky (1962)

The equation of motion of the van der Pol oscillator is again

$$
x+\alpha x+\gamma x^{2} x+\omega^{2} x=0
$$

For small nonlinearity this is very close to a simple harmonic oscillator of frequency $\omega$ The idea here is that the nonlinearity stabilizes the oscillation at a frequency not too different from $\omega$ This suggests a transformation from $x(t)$ and $x(t)$ to new variables, namely, an amplitude $r(t)$ and phase $\phi(t)(x(t)=2 r(t) \cos [\omega t+\phi(t)])$ For ease of computation, we adopt complex notation

$$
x=B(t) e^{i \omega t}+B^{*}(t) e^{-\imath \omega t},
$$

where $B$ is a complex time dependent amplitude and $B^{*}$ is its complex conjugate In this new coordınate system we can define two important approximations to the exact solution (which is unobtainable analytically) The slowly varying amplitude approxımation amounts to assuming $|B| \ll \omega B$ and is used in a self-consistent manner (see below) The rotatıng wave approxımation (RWA) consısts of neglectıng terms higher in frequency than the fundamental, such as $e^{3 / \omega t}, e^{-3 / \omega t}$, and so forth This means that the anharmonicity of the solution is neglected (this is why the RWA is sometımes also called the harmonic balance approxtmation) See, for example, Haken (1985) for a physical interpretation of these approximations Using Equation $\mathrm{A} 1$ and these two approximations we obtain for Equation A1

$$
B=-\frac{\alpha B}{2}-\frac{\gamma|B|^{2} B}{2}
$$

Introducing polar coordinates in the complex plane,

$$
B(t)=r(t) e^{i \phi(t)},
$$

and separatıng real and imaginary parts we find

$$
\begin{aligned}
& r=-\frac{\alpha r}{2}-\frac{\gamma r^{3}}{2} \\
& \phi=0
\end{aligned}
$$

Equation AS for the radius $r$ of the limit cycle (which here is a limit circle in the complex plane due to the RWA) has a form that makes visualization of its solutions very simple-namely, it corresponds to the overdamped movement of a particle in the potential

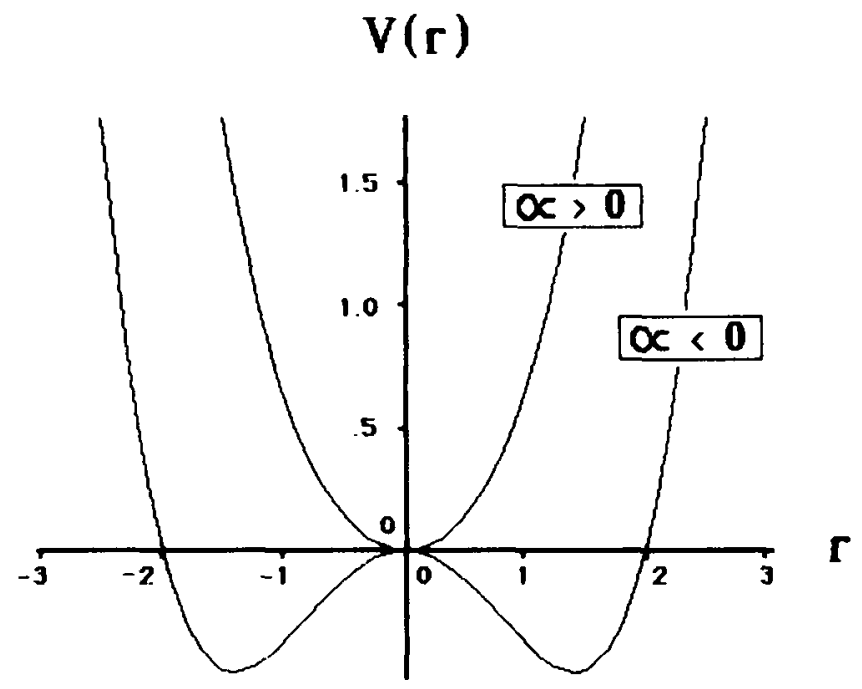

Figure A1 Amplitude potential, $V$, as a function of the amplitude, $r$, for the van der Pol oscillator, when $\alpha$ is less than zero and greater than zero (Units are arbitrary [see Appendix B] )

$$
V(r)=\frac{\alpha r^{2}}{4}+\frac{\gamma r^{4}}{8}
$$

This potential is illustrated in Figure AI for $\alpha>0$ and for $\alpha<0$, while $\gamma>0$ in both cases

Obviously for $\gamma>0$, the limit cycle of finite amplitude,

$$
r_{0}=\sqrt{|\alpha| / \gamma}
$$

is a stable, statıonary solution A movement with an amplitude close to $r_{0}$ relaxes to the limit cycle according to

$$
r(t)=\left(r(t=0)-r_{0}\right) e^{-\alpha t}+r_{0}
$$

(as can be seen by linearization of Equation A5 around $r=r_{0}$ ) Thus this amplitude varies slowly, as long as $|\alpha| \ll \omega$ This is the above-mentioned self-consistency condition The time $(1 /|\alpha|)$ is called the relaxation time of the amplitude Equation A6 of the relative phase shows that phase is marginally stable, that is, does not return to an initial value if perturbed This can be tested in phase resetting experiments as explained in the General Discussion 


\section{Appendix B}

\section{Dimensional Analysis of Hybrid, Nonlinear Oscillator}

Here we perform a dimensional analysıs to compare different contr1butions to the oscillator dynamics To that end we estımate the different forces in the equation of motion (Equation 5) by their amplitudes when the system is on the limit cycle The linear restoring force behaves as

$$
\omega^{2} x \approx \omega^{2} r_{0},
$$

where $r_{0}$ is the radius of the limit cycle The linear (negative) damping IS

$$
\alpha x \approx \alpha \omega r_{0}
$$

The van der Pol nonlinearity is

$$
\gamma x^{2} x \approx \gamma \omega r_{0}^{3},
$$

while the Rayleigh nonlinearity scales as
Usıng Equation 6,

$$
\beta x^{3} \approx \beta \omega^{3} r_{0}^{3}
$$

$$
r_{0}=2 \sqrt{|\alpha| /\left(3 \beta \omega^{2}+\gamma\right)}
$$

as the radius of the hybrid limit cycle, the strength of the nonlinear dissipative terms relative to the linear restoring term is

$$
\frac{\beta x^{3}+\gamma x^{2} x}{\omega^{2} x} \approx \frac{\alpha\left(\beta \omega^{2}+\gamma\right)}{\omega\left(3 \beta \omega^{2}+\gamma\right)}
$$

For either of the simple oscillators this reduces to $\alpha / \omega$

Received March 17, 1986

Revision received August 15, 1986 